Article

\title{
Developing and Piloting a Pedagogy for Teaching Innovation, Collaboration, and Co-Creation in Secondary Education Based on Design Thinking, Digital Transformation, and Entrepreneurship
}

\author{
Athanassios Androutsos ${ }^{1, *}$ and Vasiliki Brinia ${ }^{2}$ \\ 1 Teacher Education Programme, Department of Informatics, School of Information Sciences and Technology, \\ Athens University of Economics and Business, 10434 Athens, Greece \\ 2 Scientific Responsible of Teacher Education Programme, Department of Informatics, School of Information \\ Sciences and Technology, Athens University of Economics and Business, 10434 Athens, Greece; \\ vbrinia@aueb.gr \\ * Correspondence: thanasis@aueb.gr
}

Received: 3 May 2019; Accepted: 21 May 2019; Published: 23 May 2019

check for updates

\begin{abstract}
In Secondary Education, students need innovative skills and competences that the current education system does not sufficiently offer. Also, educators need pedagogical support to develop teaching to respond to 21 st century skills requirements. In order to achieve these goals, an experimental culture of learning needs to be implemented in practice. The aim of this paper is to introduce and pilot a pedagogy for teaching innovation, collaboration, and co-creation in secondary education. The proposed pedagogy is based on a designerly way of thinking, digital competences, and entrepreneurial spirit, together with an experimental culture of creating, making, and collaborating in order to improve students' innovative, co-creative and collaborative way of thinking and making. The main finding is that the proposed pedagogy enhanced innovative, collaborative and co-creative student competences. Moreover, digital and entrepreneurial skills gave the ability to the students to create new valuable products and services.
\end{abstract}

Keywords: design thinking; pedagogy; innovation; collaboration; co-creation; education; digital skills; entrepreneurship

\section{Introduction}

UNESCO, in its 2030 agenda, considers creativity, entrepreneurship, and innovation as key enablers for sustainable development [1-5]. However, entrepreneurship, creativity, and innovation cannot be sufficiently offered by the current education and schooling system. In the current education system, creativity, and innovation are not valued enough, while failure is stigmatized. In order to foster entrepreneurship young adults and future innovative entrepreneurs should not be limited by fear of failure. Moreover, there is a gap between real-world needs and the current education methods and practices regarding the current and future societal and economic phenomena [6,7]. This paper aims to empower teachers of secondary education to find a new pedagogy to teach creativity, innovation, collaboration, and co-creation in a 'out of the school doors' approach together with a proposed toolkit that involves, design thinking practices, digital tools, and entrepreneurial way of thinking.

We could shape the big picture in today's education system as being formed by three separate circles (see Figure 1): (i) Circle 1, Real-world problems and needs, (ii) Circle 2, Skills and competences required by economy and society, and (iii) Circle 3, Skills and competences provided by the current schooling system. 


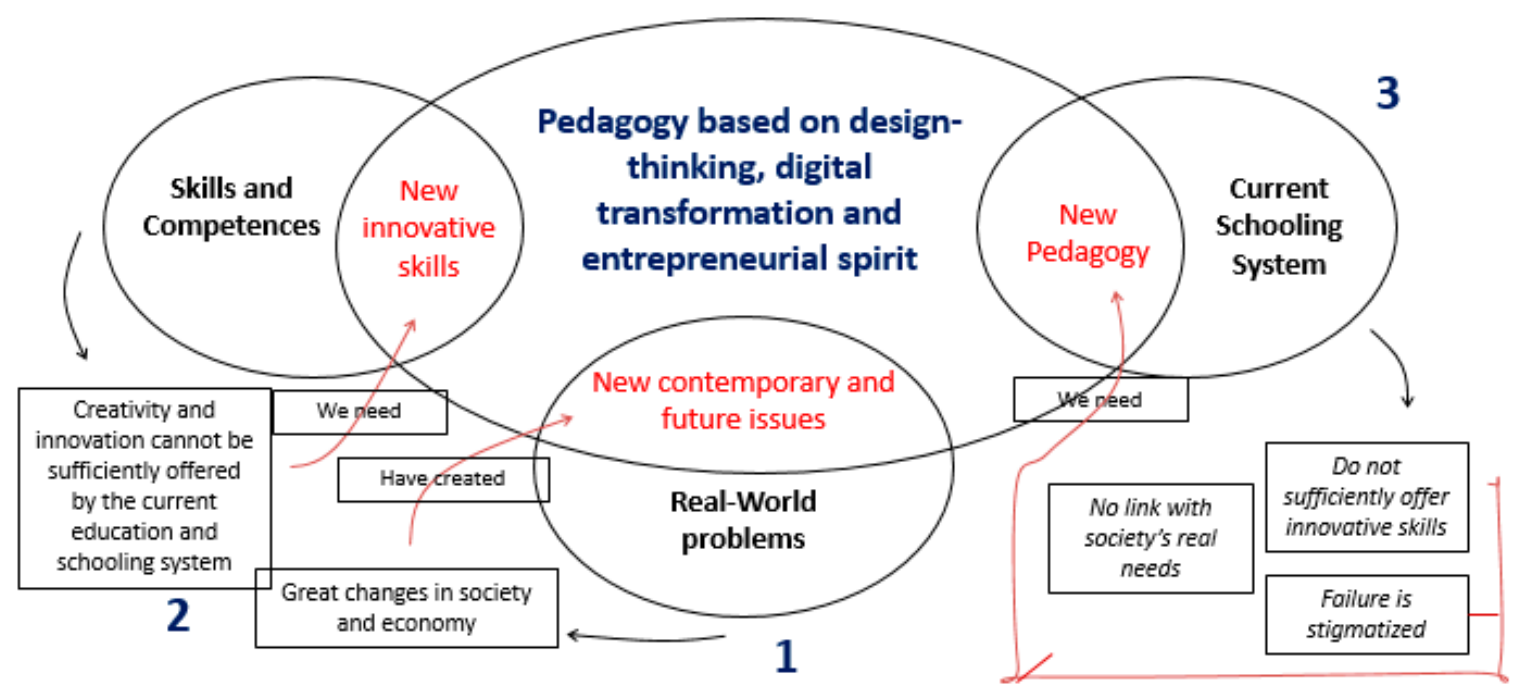

Figure 1. The conceptual model of the proposed pedagogy.

Due to substantial changes in the economy, technology, and society, in the emerging digital economy, new problems have been arisen that require a new set of skills -mainly creativity, innovation, and co-creation- in order to be tackled efficiently.

The proposed pedagogy is a joint approach based on designerly way of thinking, digital transformation and entrepreneurial spirit that ties together the three separated circles by providing a new pedagogy for the schooling system that gives the opportunity to the youth to develop innovative skills in an experimental way by collaboratively and co-creatively addressing real-world problems and designing solutions to new contemporary and futures issues.

There are many competences frameworks that mention innovation, collaboration, and co-creation as the skills of 21st century. The OECD Key Competences framework [8] focuses on collaboration, digital tools, and the interaction with users as the key competences for the youth, young adults, and the human capital of the economy. The OECD Global Competence framework refers and stresses the importance of user interaction with empathy in a global level (i.e., empathy is the main feature in design thinking user analysis) [9]. The P21 framework, which is a US framework, focuses on innovative and digital skills regarding 21st century skills [10]. The World Economic Forum also targets on creativity and ICT skills as fundamental competences for the labor market [11].

An essential pillar for innovation in digital economy is technology. Advanced digital skills are regarded as core skills in 21st century and mentioned in several competences frameworks such as European Commission's-DigComp 2.0 and DigComp 2.1 [12,13]; OECD Skills for a digital world [14]; UNESCO-Managing tomorrow's digital skills [15]; OECD-G20—Key issues for digital transformation [16]; Capgemini and LinkedIn-The digital talent gap [17]; and European Parliament-Digital skills in the 21st century [18].

The 21st century innovative and digital skills are essential skills for designing solutions to real-world problems and thus are considered fundamental competences for creating new valuable products or services. Entrepreneurial skills should also be considered essential 21st century skills as it is described in several competences' frameworks and reports such as EntreComp (The Entrepreneurship Competence Framework) [19] and other frameworks regarding sustainable development goals [20,21].

Based on the above considerations, the challenge and the fundamental question is how to teach those competences in a way that will make an impact in students' future skillset. The proposed pedagogy responds to this challenge by providing an experimental framework that gives the opportunity and the tools to the students to acquire these skills in an empirical way by developing solutions and business ideas and thus gaining the ownership of the process.

The proposed pedagogy was developed and piloted as part of the Teacher Education Programme (TEP) of Athens University of Economics and Business (AUEB), which is a one-year undergraduate 
Programme that provides research-based pedagogical training to tomorrow's secondary education teachers in the fields of economics and technology.

The main goal was to develop a concrete methodology that would allow students to find innovative solutions to real problems and exploit entrepreneurial thinking based on a designerly way of thinking and making, digital tools, and entrepreneurial skills. At the same time the educational community should be expanded and create a wider community of common interests that would involve enterprises, organizations or nonprofit organizations in order to apply an 'out of the school doors' approach and give the opportunity to the students to address problems of the real economy. The hope was that the students through that process would acquire innovative, collaborative and co-creative skills and competences in an experimental and real-world way.

Design thinking could be regarded as a project-based methodology [22,23], but with significant differences. First, the focus in design thinking is on creating new knowledge and innovative solutions through co-creation, that is, through collaboration with the users and the other members of the community of common interests. Co-creation through user participation is the process of designing a product or service together with the users; it is mainly a user-centric approach [24]. In the designerly way of thinking, the interaction with the users should involve empathy in order to realize users' needs and thus design an overall user experience. Since interaction with the users is considered an ill-defined process, design thinking also involves observation of users' activity and way of thinking and doing. Thus, innovation mainly comes through empathy-based user analysis and co-design process that tries to fit together user needs and business goals in a feasible, desirable and viable way.

Design thinking in educational practice leads students-through an artful and experiential way of thinking and doing - to be much more creative and innovative, and also be more responsible by allowing them having the ownership of the creation process. The role of digital tools and skills in this area is to prototype solutions, develop innovative ideas and provide feasible solutions with societal and economic impact. Making prototypes, artifacts, services, and products by using digital technology towards a more innovative world is a method for creating new knowledge and opportunities. Entrepreneurial competences for digital economy is about exploring opportunities and applying business ideas thus enhancing societal and economic involvement and responsibility $[25,26]$.

\section{Methodology}

\subsection{The Methodology}

The proposed pedagogy builds on the double-diamond methodology [27] and designerly ways of thinking [28]. Double diamond is a design process for solving real-world problems, based on divergent and convergent thinking both for the definition and solution of a problem. Designerly way of thinking which is based on double-diamond methodology has been used in education $[29,30]$ for solving real-world phenomena with promising results. The main idea of design thinking in education is to engage groups of students in the process of determining a real-world problem and then through an experimental way of thinking and making to be able to design a solution.

In collaboration with the Department of Informatics of AUEB, TEP students are educated in designerly ways of thinking and making, by using digital technologies and digital tools. TEP students are also very much aware of the way that secondary students think and act, their beliefs, fears, knowledge, and competences due to their several scheduled visits (as teachers) to schools that are part of their standard TEP-AUEB Programme requirements.

This dual role of TEP students (both as secondary education teachers and TEP students) gave us the opportunity to design a holistic pedagogy taking into account both requirements. Although the pedagogy was designed and delivered to a wide audience of about fifty (50) students, in this paper, we have run a pilot and measured the results of a single students' team made up of five (5) students that were assigned a coursework based on the proposed pedagogy. The pedagogy was designed and applied accordingly while at the same time we measured the gaining of students in terms of innovative, 
collaborative, and co-creative competences. The hope was that if the gain was significant, then the pedagogy could be scaled up and tested in a wider audience.

What was initially asked by the team of TEP students was to design a solution to a real-world problem. Initially, in the first stage of the methodology, the students were asked (i) to identify an area of interest and (ii) to form smart teams based on members' common interests and character proximity. With regard to team formation, the students were asked to involve team-members that come from different disciplines.

They were also asked to combine the chosen field of research with their own learning interests since TEP-AUEB Programme involves students from the whole AUEB undergraduate spectrum, i.e., from all the eight undergraduate departments, namely Departments of Informatics, Statistics, Business Administration, Management Science and Technology, Accounting and Finance, Marketing and Communication, International and European Economic Studies, and Economics.

Moreover, during the first stage of the pedagogy, the student team was asked to search, find, and organize information by using Web or other sources and then based on that information to focus on a specific and current issue or problem that they were interested in. The whole informational organization process should be supported by web-based tools such as Evernote. The web sources and information should be saved and organized in a proper way by using tags in order to apply semantics to the information in order to be easily findable in a later time. Also, in the first phase of the pedagogy students were asked to provide a brief project proposal.

After that, the students should collaborate with a supporting organization, that is, a company, organization, or NPO (Non-Profit Organization) with the same interests in order to create a wider community with common interests. This step was extremely important since it gave the opportunity to the students to come closer to the real market, talk with mentors, and collaborate with many business people. The degree of difficulty to find an official body to collaborate with was low since most of the enterprises and other market agents were very willing to participate in a project that would potentially provide fresh ideas to their problems.

In the second phase, the students were asked to provide a Gantt chart of their project divided in Work-Packages and tasks and the time scheduling of their planned work, by using a well-known digital tool (i.e., MS Project). At the same time, the team was asked to provide a mind map by using an open source digital tool (i.e., freemind) in order to visualize the information of the project. It is important in our proposed pedagogy, to visualize the information (gathered by multiple sources) in a nonlinear way, and thus gradually draw a big and rich picture of the project. At the 2nd phase of the pedagogy, the students should also implement the users' analysis phase through interviews and observation. They should arrange personal interviews with potential users (of the product or service that TEP students were intending to design and implement) in order to analyze users' preferences, way of thinking and feelings with empathy. They were asked to explore extreme users, average users, and users that do not use similar services or products or are not aware of the designed service or product. The interview process was organized by using forms and standard templates that were given the opportunity to the users to sketch their thoughts and feelings, in a visual way and, also, investigate and visually design a range of possible solutions. In this stage, the crucial point is the users' participation in the design of the product or service. The design should be visual or tangible.

The team should perform three interview iterations with the users. At each iteration cycle, the students' team should reduce the range of possible solutions based on users' feedback. The student team should also be aware that if during the analysis phase it was realized that the problem under consideration was not consistent with users' way of thinking, the problem should be restructured and redefined. Hence, in such a case, the project should return in its initial phase and consider a new problem.

It is thus crucial for the consistency of the whole methodology not to give the right solution to the wrong problem, but to carefully consider and solve the right problem. It is also crucial and also desirable to fail early in order to be able to proceed faster and better. This point is crucial, since it 
differentiates the methodology from the current way of thinking and doing in most schooling systems that involve in their assessment practices the fear of failure.

While co-creation phase was running, the team was advised to have frequent brainstorming sessions in order to discuss and evaluate the range of potential solutions. Students were asked to maximize divergence in the solutions space by discussing and evaluating many different potential solutions. They were asked to critically evaluate each solution with respect to certain constraints; mainly three constraints: technical feasibility, economic viability, and users' desirability.

TEP students were also asked to have a workshop with the supporting company and people in order to evaluate the technical feasibility and economic viability of the solutions.

At the same time, the students were also asked to document each step of the process in the field of research with photos, text, video, and audio by using their mobile phones. Next, they were asked to insert the critically evaluated information in a presentation file such as PowerPoint (having first edited the media files with appropriate open-source digital tools such GIMP for photo editing, Audacity for audio editing, and Avidemux for video editing), in order to create a 'story'. Multimedia documentation of the process is very important for developing the story of the project and for sharing students' ideas and thus the students were asked to carefully perform this process with respect to GDPR (General Data Protection Regulation). At the end of the design phase, the TEP students should demonstrate their designed solution, the prototype, and provide the documentation.

The next and final phase includes the development of a business plan for transforming user needs to demand. The students should also visualize the process they followed; they were asked to produce an annotated videocast of the whole process by using the already developed presentation file and an open-source video-capturing tool such as OBS (Open Broadcaster Software). The goal was to produce a 'story' of their project. Then, they should share that video through social media, websites and other channels for sharing their ideas and their 'story', as part of the exploitation of the results.

The main goal in the exploitation phase is to develop a business plan based not only on the 'what' the solution is, nor on 'how' it was designed, but mainly and mostly on 'why' the students wanted to solve this particular problem; what was their motivation, their dream. This 'why' would firstly be their final shared story, and then this story would be combined with 'how' the solution was developed and 'what' the service or the product will be.

\subsection{Data Collection}

In this paper we have analyzed the data collected by five students that made up a team to address a real-world problem that was given as part of the coursework of the module "Digital educational content creation \& usage, in contemporary learning methodologies", 7th semester, Teacher Education Programme of Athens University of Economics and Business (https://www.dept.aueb.gr/en/tep). The real problem that the TEP students dealt with was the diabetes problem and the inability of the patients to implement a consistent diet in order to address their problem efficiently. The students' team followed the proposed methodology and the solution that was proposed was an android app that is advising the patients on their daily diet based on their habits and the data that the patients themselves have provided to the app regarding their daily diet preferences, specific food that they would like to exclude, etc.

The data analysis is based on the opinion of the students regarding the skills they acquired during running the proposed pedagogy. The data analysis is based on the opinion of the students that ran the methodology as a result of a Likert scale applied to a questionnaire with ten questions. Part of the questionnaire was based on DARPA Hard Test (DHT) in order to determine an innovative score for students' prototype. The DHT is a test used at DARPA to evaluate the breakthrough potential of a technology and has since been adopted as an innovation tool for team-based projects [31]. 


\subsection{Questionnaire}

In order to evaluate the effect of the pedagogy, a questionnaire was designed and the students that made-up the team and ran the proposed pedagogy were asked to answer and rate the questions on a Likert scale from 1 to 7 (1-I do not agree at all; 7-I totally agree). The number of participants who answered the Questionnaire was 5 (females). The scale was based on DARPA scaling and the skills acquired level was considered 'high' if the score was between 5-7 and 'low' if it was between 1-4.

The first four questions implement the DARPA Hard Test (DHT) and measure the degree of innovation of the final solution. Question 1 measures the degree to which the solution to the problem is Far-Reaching, Question 2 measures the degree to which the proposed solution is Technically Challenging, Question 3 measures the Multi-Disciplinary dimension of the solution and Question 4 measures the degree to which the proposed solution is actionable.

The next two questions, Questions 5 and 6, measure the degree of impact of collaboration and co-creation on the final innovation.

The next four questions, Questions 7-10, measure the skills and competences acquired through the proposed pedagogy in comparison with legacy teaching methods.

The questions posed to the students are as follows.

1. Does the final solution require a paradigm shift in how it is considered across society?

2. Does the final solution require major advances in technical knowledge?

3. Does the final solution require multiple, distinct bodies of knowledge?

4. Does the final solution require little effort to begin taking action towards the solution?

5. Does collaboration between team members affected positively the innovative index?

6. Does co-creation between the team and the users affected positively the innovative index?

7. Does the implemented pedagogy lead to a greater degree of acquired innovative skills in comparison with other methods that you were taught during your educational life?

8. Does the implemented pedagogy lead to a greater degree of acquired collaborative skills in comparison with other methods that you were taught during your educational life?

9. Does the implemented pedagogy lead to a greater degree of acquired co-creative skills in comparison with other methods that you were taught during your educational life?

10. Does the implemented pedagogy provide a greater motivation to be innovative in comparison with other methods that you were taught during your educational life?

The results obtained are represented in the bar charts depicted in Figure 2.

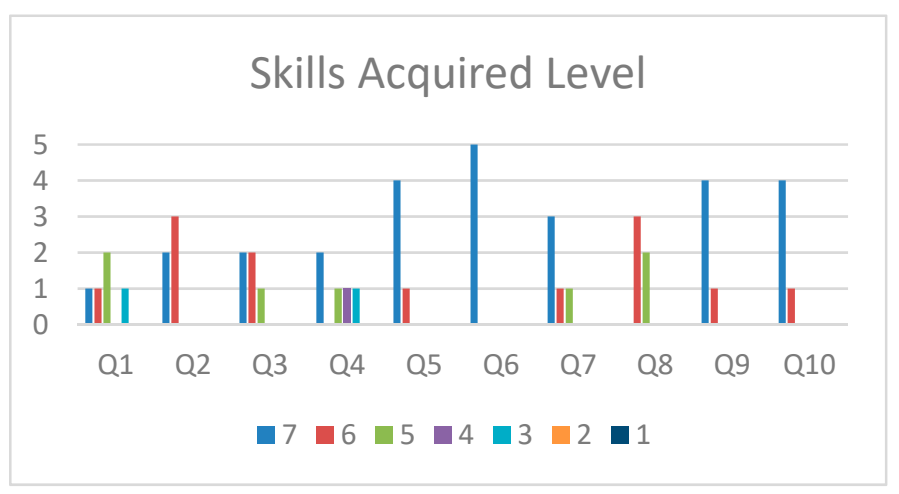

Figure 2. Joint DARPA/Likert scale bar graph for each answered question.

Regarding the questions asked, we calculated the percentage of skills-acquired level on the basis: 'high', if the score was between 5 and 7 and 'low', if it was between 1 and 4 . All questions had a 100\% high, except question 1 (whether the solution is far-reaching)—High $80 \%$, Low 20\%-and question 4 (whether the solution is easily actionable): High 60\%, Low $40 \%$. 


\section{Results and Implications}

\subsection{The Results}

The results of the analysis are presented in Table 1.

Table 1. Results from the joint DARPA/Likert scale test performed to investigate the relationship between the innovation index (DARPA Hard Test (DHT), Questions 1-4) the collaboration and co-creation level (Questions 5,6) of the proposed pedagogy and the relationship between legacy pedagogical approaches and the proposed pedagogy (Questions 7-10).

\begin{tabular}{|c|c|c|c|c|c|c|}
\hline \multirow{2}{*}{\multicolumn{2}{|c|}{ Question Number }} & \multicolumn{2}{|c|}{ DARPA Test Score } & \multirow{2}{*}{$\begin{array}{l}\text { Min Choice } \\
\text { Number of } \\
\text { Students in } \\
\text { Parentheses }\end{array}$} & \multirow{2}{*}{$\begin{array}{l}\text { Max Choice } \\
\text { Number of } \\
\text { Students in } \\
\text { Parentheses }\end{array}$} & \multirow{2}{*}{$\begin{array}{c}\text { Weighted } \\
\text { Average }\end{array}$} \\
\hline & & $\begin{array}{c}\text { Low (1-4) } \\
\text { (Percentage) }\end{array}$ & $\begin{array}{c}\text { High (5-7) } \\
\text { (Percentage) }\end{array}$ & & & \\
\hline \multirow{4}{*}{$\begin{array}{c}\text { DARPA } \\
\text { Hard } \\
\text { Test }\end{array}$} & Q1 & $20 \%$ & $80 \%$ & $3(1)$ & $7(1)$ & 5.2 \\
\hline & Q2 & $0 \%$ & $100 \%$ & $6(3)$ & $7(2)$ & 6.4 \\
\hline & Q3 & $0 \%$ & $100 \%$ & $4(1)$ & $7(2)$ & 6.2 \\
\hline & $\mathrm{Q} 4$ & $40 \%$ & $60 \%$ & $3(1)$ & $7(2)$ & 5.2 \\
\hline \multicolumn{2}{|c|}{ Q5 } & $0 \%$ & $100 \%$ & $6(1)$ & $7(4)$ & 6.8 \\
\hline \multicolumn{2}{|c|}{ Q6 } & $0 \%$ & $100 \%$ & - & $7(5)$ & 7 \\
\hline \multicolumn{2}{|c|}{ Q7 } & $0 \%$ & $100 \%$ & $5(1)$ & $7(3)$ & 6.4 \\
\hline \multicolumn{2}{|c|}{$\widehat{\mathrm{Q}} 8$} & $0 \%$ & $100 \%$ & $5(2)$ & $6(3)$ & 5.6 \\
\hline \multicolumn{2}{|c|}{ Q9 } & $0 \%$ & $100 \%$ & $6(1)$ & $7(4)$ & 6.8 \\
\hline \multicolumn{2}{|c|}{ Q10 } & $0 \%$ & $100 \%$ & $6(1)$ & $7(4)$ & 6.8 \\
\hline
\end{tabular}

The purposes of this quantitative study are to measure (i) the degree of innovation index (Q1-Q4), (ii) the innovative skills acquired in comparison with legacy pedagogies (Q7and Q10), (iii) the collaborative skills with regard to innovation (Q5) and in comparison with legacy pedagogies (Q8), and (iv) the co-creation contribution to innovative solution (Q6) and in comparison with legacy pedagogies (Q9).

The average score for each one of the ten questions is high, a result that shows that the proposed pedagogy's worth gets implemented and tested in a wider audience. However, the innovation index (Q1-Q4) has a relatively low min in Q2 and Q4, something that is an indication that the pedagogy has to be carefully optimized in two points: First, since the paradigm shift that is captured in Q1 is relatively low, we have to consider the introduction of art-based practices in the proposed pedagogy in order to lead to more designerly innovative solutions and provide even more innovative skills to the students. Second, since the score in Q4 is relatively low, it could be an indication that the proposed pedagogy should be further tailored to include more sophisticated support to the students on designing the transition from project room to the market.

However, in terms of competences' gain, the proposed pedagogy develops innovative and co-creative skills much better than the legacy approaches (Q7 and Q9) and collaborative skills better than the legacy approaches (Q8). Moreover, in the context of innovation, collaboration (Q5) seems to work much better than the legacy approaches. The greater gain seems to come from co-creative skills (Q6 and Q9). Co-creation is the most powerful feature in designing innovative solutions and when combined with digital tools and designerly approaches offer greater motivation to work towards innovative solutions (Q10).

\subsection{Enriched Framework and Research Implications}

There are a number of other variables that have influenced our research and play a part in preparing TEP-AUEB students to teach the proposed pedagogy. Since we are aiming to strengthen innovation, we have introduced into TEP-AUEB Programme art-based practices by allowing TEP-AUEB students to be actively engaged in producing art-based artifacts in collaboration with Athens School of Fine Arts. 
Also, in order to empower collaboration, TEP-AUEB students are actively participating in organizing public events that require students' collaboration such as TEP Annual Conferences. A sample of these innovative and collaborative activities can be found here: https://www.dept.aueb.gr/en/node/17412/.

A direct implication of this new pedagogical approach for teaching innovation, collaboration and co-creation is that it also fosters a new type of thinking for youth employment as well as for responsible economic growth and economic well-being. Since the proposed pedagogy is a skills-based approach it aims on creating the 21st century skills that are needed in future jobs. In this context, entrepreneurship plays a dual role in the proposed pedagogy.

First, entrepreneurship learning teaches young people to not be deterred by fear of failure and see entrepreneurship as a career choice. Second, apart from market agents and businesses that provide real-world problems to our students, social entrepreneurship is also introduced in the proposed pedagogy. By collaborating with nonprofit organizations we enhance social entrepreneurship and create social and economic values such as employment development, innovation capacity, new products and services, social capital, social trust, and equity promotion, thus providing to TEP-AUEB students a leading-edge collaborative and inclusive environment, which allows the pedagogical conceptualization and realization of social economy. As a consequence, TEP-AUEB students increase their understanding of social value and at the same time we contribute to the provision of employment opportunities to the disadvantaged segments of society.

A limitation of the proposed pedagogy is that the quantitative evaluation was taken from adult participants. The hope is that the generalization of the approach will have the same good results in terms of innovative, co-creative, and collaborative competences. We indent to pilot the proposed pedagogy to the students of secondary schooling system as part of TEP students teaching scheduling.

Another limitation is the number of participants that were answered the questionnaire. Since this study mainly focused in designing the proposed pedagogy, the primary goal was first to pilot the pedagogy and then, in a later phase, to implement it in a wider audience. The implementation in a wider audience is already taking place during the 2nd semester of TEP Programme in 2019, and the results will be gathered, evaluated, and presented in upcoming studies.

Finally, the proposed pedagogy focuses on the fields of economics, management, and new technologies, and deals with real-world problems that involve one or more dimensions in the above areas.

\section{Discussion}

The proposed pedagogical approach is very promising in terms of innovative, co-creative and collaborative skills that the students acquired and essentially leads to better results than other teaching approaches, such as project-based and design thinking pedagogies [32,33].

The main lack of the legacy approaches seems to be the absence of the co-creation and entrepreneurial dimensions. Another disadvantage of these approaches is the focus on tangible solutions while our approach focuses on digital solutions. Moreover, project-based and designerly approaches that lack co-creative and entrepreneurial features do not lead to advanced 21st century skills acquisition and thus should probably be of limited use.

An important feature for improving the innovation index seems to be, first, the art-based practices for improving the 'out of the box' way of thinking and thus promoting innovative design solutions and, second, the improvement of the exploitation plan in order to be easily applicable and transferable to the market. Although both fields are part of TEP-AUEB Programme must carefully be reconsidered in the revised version of the proposed pedagogy.

However, based on the pilot that we have run, the proposed pedagogy enhances innovative, collaborative, and co-creative student competences and it is superior to any other teaching method that the students had been taught in the past. That is a very important signal that the proposed pedagogy could be used as a basis for the youth, educators, and businesses to tackle real-world issues in and outside the school by using, design, digital, and entrepreneurial methods. 
Based on the findings of the current research, our future research will focus on the following topics; (i) the way that our approach could be applied, evaluated, and refined together with secondary education students and teachers in order to impact future everyday life at schools, (ii) how educational policies could be reformed in order to promote the collaboration between schools, enterprises and nonprofit organizations, and (iii) how Europe's demand for human capital and high growth rates could be combined with an educational model that will produce individuals with fresh ideas, advanced skills, and, at the same time, responsible citizens and entrepreneurs.

\section{Conclusions}

The proposed pedagogy introduces a framework for teaching innovation, collaboration and co-creation in secondary education based on design thinking, digital transformation, and entrepreneurial way of thinking. The pedagogy includes concepts and tools to be used both in and outside the school.

The basic approach aims to empower students to communicate with users with empathy in order to realize the constraints of a real-world problem, possibly restructure it, and then co-design and co-create, together with the users, a solution to this problem. This process is mainly a user-centric experimental process since it involves exploration and investigation of many alternative designs through three iterative cycles of ideation, user feedback, evaluation, and ideas refinement. The hope and the expectation is that the final solution will be innovative, since during this process new ideas are born, developed, and tested in order to appropriately address user needs in a user-desirable, technically feasible, and economically viable way. The most important, during this process the students acquire the 21st century skills that are needed in future jobs.

The proposed pedagogy was developed and piloted in the context of Teacher Education Programme of Athens University of Economics and Business (TEP-AUEB) with the participation of (i) TEP-AUEB students, (ii) users of the real economy that were acting as potential consumers of the products or services, but also as co-designers, and (iii) organizations and enterprises that were willing to participate and create a wider community of common interests.

The results of the pilot are very promising. The main finding of the research which was performed by using a joint DARPA/Likert scale approach- is that the rating of the skills-acquired level was high (i.e., average score 5-7) in all cases and that the proposed pedagogy is superior to any other pedagogy that the students had been taught in the past during their educational life.

Author Contributions: conceptualization, A.A.; methodology, A.A.; software, A.A.; validation, A.A.; formal analysis, A.A.; investigation, A.A.; resources, A.A. and V.B.; data curation, A.A.; writing-original draft preparation, A.A.; writing-review and editing, A.A. and V.B.; visualization, A.A.; supervision, A.A. and V.B.; project administration, A.A. and V.B.

Funding: This research received no external funding.

Acknowledgments: Special thanks to Anna Michalopoulou, Anna Kondea, Stavroula Chatzidimitriou, Eleni Pefani and Georgia Doulgeraki which are the TEP-AUEB students that performed the coursework and answered the questionnaire.

Conflicts of Interest: The authors declare no conflict of interest.

\section{References}

1. UNESCO and Sustainable Development Goals. United Nations Education Science and Culture Organization. Available online: https://en.unesco.org/sdgs (accessed on 22 May 2019).

2. United Nations 2030 Agenda for Sustainable Development. United Nations Education Science and Culture Organization. Available online: https://sustainabledevelopment.un.org/content/documents/21252030\% 20Agenda\%20for\%20Sustainable\%20Development\%20web.pdf (accessed on 22 May 2019).

3. UNESCO. Intercultural Competences Framework. 2013. Available online: https://unesdoc.unesco.org/ark: /48223/pf0000219768/PDF/219768eng.pdf.multi (accessed on 22 May 2019). 
4. UNESCO. Guiding Principles for Learning in the Twenty-First Century. Available online: http://www.ibe. unesco.org/sites/default/files/resources/guiding_principles_brochure_eng.pdf (accessed on 22 May 2019).

5. UNESCO. Towards Universal Learning. 2013. Available online: https://unesdoc.unesco.org/ark:/48223/ pf0000219763/PDF/219763eng.pdf.multi (accessed on 22 May 2019).

6. OECD. Future of Education and Skills, Education 2030. 2018. Available online: https://www.oecd.org/ education/2030/E2030\%20Position\%20Paper\%20(05.04.2018).pdf (accessed on 22 May 2019).

7. European Commission, Council Recommendation on Key Competences for Life-Long Learning. 2018. Available online: http://data.consilium.europa.eu/doc/document/ST-5464-2018-ADD-2/EN/pdf (accessed on 22 May 2019).

8. OECD. The Definition and Selection of Key Competences, (DeSeCo). 2005. Available online: https: //www.oecd.org/pisa/35070367.pdf (accessed on 22 May 2019).

9. OECD. Global Competency for an Inclusive World. 2016. Available online: https://www.oecd.org/education/ Global-competency-for-an-inclusive-world.pdf (accessed on 22 May 2019).

10. The Partnership for 21st Century Skills, Framework for 21st Century Learning Definitions. Available online: http://static.battelleforkids.org/documents/p21/P21_Framework_DefinitionsBFK.pdf (accessed on 22 May 2019).

11. World Economic Form and Boston Consulting Group. New Vision for Education: Unlocking the Potential of Technology. 2015. Available online: http://www3.weforum.org/docs/WEFUSA_NewVisionforEducation_ Report2015.pdf (accessed on 22 May 2019).

12. European Commission. Digcomp 2.0 the Digital Competence Framework for Citizens. 2016. Available online: http://publications.jrc.ec.europa.eu/repository/bitstream/JRC101254/jrc101254_digcomp\%202.0\% 20the $\% 20$ digital $\% 20$ competence $\% 20$ framework\%20for\%20citizens. $\% 20$ update $\% 20$ phase $\% 201$.pdf (accessed on 22 May 2019).

13. European Commission. Digcomp 2.1 the Digital Competence Framework for Citizens. 2017. Available online: http://publications.jrc.ec.europa.eu/repository/bitstream/JRC106281/web-digcomp2.1pdf_(online) .pdf (accessed on 22 May 2019).

14. OECD. Skills for a Digital World. 2016. Available online: https://www.oecd.org/els/emp/Skills-for-a-DigitalWorld.pdf (accessed on 22 May 2019).

15. UNESCO. Building Tomorrow's Digital Skills: What Conclusions Can We Draw from International Comparative Indicators? Available online: https://unesdoc.unesco.org/ark:/48223/pf0000261853/PDF/ 261853eng.pdf.multi (accessed on 22 May 2019).

16. OECD-G20. Key Issues for Digital Transformation in the G20. Available online: https://www.oecd.org/g20/ key-issues-for-digital-transformation-in-the-g20.pdf (accessed on 22 May 2019).

17. The Digital Talent Gap, Gapgemini, LinkedIn. 2017. Available online: https://www.capgemini.com/wpcontent/uploads/2017/10/Digital-Talent-Gap-Report_Digital.pdf (accessed on 22 May 2019).

18. European Parliament. Digital Skills in the 21st Century. 2018. Available online: http://www.europarl.europa. eu/RegData/etudes/STUD/2018/617495/IPOL_STU(2018)617495_EN.pdf (accessed on 22 May 2019).

19. European Commission. EntreComp: The Entrepreneurship Competence Framework. 2016. Available online: http://publications.jrc.ec.europa.eu/repository/bitstream/JRC101581/lfna27939enn.pdf (accessed on 22 May 2019).

20. Allen, C.; Clouth, S. A Guidebook to the Green Economy; Issue 1: Green Economy, Green Growth, and Low Carbon Development_-History, Definitions and a Guide to Recent Publications; UN Division for Sustainable Development: New York, NY, USA, 2012; Available online: https://sustainabledevelopment.un.org/content/documents/ GE\%20Guidebook.pdf (accessed on 22 May 2019).

21. Youssef, A.B.; Boubaker, S.; Omri, A. Entrepreneurship and Sustainability Goals: The Need for Innovative and Institutional Solutions. Technol. Forecast. Soc. Chang. 2018, 129, 232-241. [CrossRef]

22. Brown, T. Change by Design: How Design Thinking Transforms Organizations and Inspires Innovation, Harper Business; Harper Business: New York, NY, USA, 2009.

23. Brinia, V. Project: A trainee-oriented training method, an empirical approach. High. Educ. Ski. Work. Based Learn. 2011, 1, 169-186. [CrossRef] 
24. Sanders, E.B.-N. From User-Centered to Participatory Design Approaches. In Design and the Social Sciences; Frascara, J., Ed.; Taylor \& Francis Books Limited: London, UK, 2002; pp. 1-8. Available online: http://maketools.com/articles-papers/FromUsercenteredtoParticipatory_Sanders_\%2002.pdf (accessed on 22 May 2019).

25. Seitamaa-Hakkarainen, P.; Kangas, K.; Raunio, A.-M. Collaborative Design Practices in Technology Mediated Learning. Des. Technol. Educ. Int. J. 2012, 17, 54-65.

26. Vartiainen, H. Principles for Design-Oriented Pedagogy for Learning from and with Museum Objects; Publication of the University of Eastern Finland, Dissertations in Education, Humanities, and Technology No. 60; University of Eastern Finland: Joensuu, Finland, 2014.

27. Design Council. The Design Process: What is the Double Diamond? Available online: https://www. designcouncil.org.uk/news-opinion/design-process-what-double-diamond (accessed on 22 May 2019).

28. Cross, N. Designerly Ways of Knowing; Springer: London, UK, 2006.

29. Seitamaa-Hakkarainen, P.; Viilo, M.; Hakkarainen, K. Learning by collaborative designing: Technology-enhanced knowledge practices. Int. J. Technol. Des. Educ. 2008, 20, 109-136. [CrossRef]

30. Leinonen, T.; Durall, E. Design Thinking and Collaborative Learning. Media Educ. Res. J. 2014, XXI, $107-116$. [CrossRef]

31. Durão, L.F.C.; Kelly, K.; Nakano, D.N.; Zancul, E.; McGinn, C.L. Divergent prototyping effect on the final design solution: the role of "Dark Horse" prototype in innovation projects. In Proceedings of the 28th CIRP Design Conference, Nantes, France, 23-25 May 2018.

32. Krajcik, J.S.; Blumenfeld, P.C. Project-Based Learning. In The Cambridge Handbook of the Learning Sciences; Sawyer, R.K., Ed.; Cambridge University Press: Cambridge, UK, 2005; pp. 317-334.

33. Anu, L.; Jorma, E.; Sinikka, P. The case of design-oriented pedagogy: What students' digital video stories say about emerging learning ecosystems. Educ. Inf. Technol. 2014, 19, 583-601. [CrossRef]

(C) 2019 by the authors. Licensee MDPI, Basel, Switzerland. This article is an open access article distributed under the terms and conditions of the Creative Commons Attribution (CC BY) license (http://creativecommons.org/licenses/by/4.0/). 